\title{
The Role of Universities in Social Reconstruction
}

\author{
Zohreh Esmaeili
}

Assistant professor, Department of Educational Sciences and Psychology, Payame Noor University (PNU), Tehran, Iran

Asadolah Abassi

Ph.D. Student of Educational Philosophy Department of Educational Sciences and Psychology

Payame Noor University (PNU), Tehran, Iran

Sayyed Mahamad Jahfar Shahamiri

M.A in History and civilization of Islamic Nations. Occupation: principal of high school

Doi:10.5901/mjss.2015.v6n6s6p271

\section{Abstract}

The theory of social reconstruction is one of the intended theories in the major of educational philosophy that have had significant influence on the education and training and the academic centers in the west. Based on this theory, the human beings transform into the social engineers that are able to program the evolution route and use the science and technology in the case of achieving the optimum goals. Thus, the academic centers should be question-centered and be aware of the society's matters. This means that they should identify the crises of a society and equip the students for facing these crises by means of utilizing the social reconstruction role. In this regard, the present study investigates the current crises of the society. Then, it suggests 21 roles that the universities, the main centers for reconstructing the society, have to implement in order for resolving these crises; 1 - identifying, training, and guiding the new reference groups in the direction of society's optimum values; 2- refining and rebuilding the past values and according them with new valuable creations in society; 3- restructuring the Islamic patterns and texts; 4- strengthening the sense of attachment to national and bias sovereignty; 5- Reconstruction of Cultural Coexistence between different Ethnic, Religious and Linguistic Groups in 7- restructuring the coexistence culture between different ethnic groups, religions, and languages; 8- developing and training the life skills appropriate to the effects caused by industrialization and trans-industrialization; 6- strengthening the free-thinking tables 9- recruiting needed human source in the age of information and technology; 10- establishing software in the modern world media; 11- institutionalizing the respect for laws and regulation among adolescents; 12- strengthening religious and valuable norms and redefining them; 13strengthening the viewpoint of rural life versus creation of negative attitudes toward urban life; 14- preparing a comprehensive rural life program; 15- changing the adolescents' attitudes towards occupation; 16- training entrepreneuring; 17- admitting and introducing elite graduates for scientific and administrative bodies; 18- strengthening domestic self-esteem in world scenes; 19strengthening the culture of consumption of natural resources especially water resources; 20-creating and strengthening the culture of resistive economy among students; and 21 - creating environmental attitudes among students.

Keywords: Social Reconstruction, Crisis, University Role, Education and Training Philosophy.

\section{Introduction}

We live in a passing and changing world that everything is constantly changing. Probably this change is because of the power of science carrying with itself in the recent centuries specifically the $21^{\text {st }}$ and beyond devoted to the human beings. The history points of human development have been three major waves such as agriculture, industry, and information. Today the virtual era creates also the fourth wave of changing and evolution in human beings' life (Jalali, 2014). Undoubtedly although these waves of changes are alongside the growth and transformation of human life and creation of more facilities and easiness, if the human beings are not prepared for such changes, they may be indigestible and may bring decline and fall of a society culturally and socially. In all, technological growth has a close relationship with culture, social philosophy, and ethics. They are in fact two sides of a coin. It means that the dominant culture and philosophy bring about the field for the growth of technology on the one hand, and every technology entails its own culture and philosophy on the other hand in such a condition that pragmatic philosophy, even though inspired by technological changes in America, has caused the salient acceleration in technological growth in that context. This growth was so 
rapid, unexpected and stressful that some parts of a society could not adapt themselves with that type of change. For this reason, it caused some criticisms by thinkers of philosophy and sociology. Therefore, if such a social, political and cultural change was not in line with the technological development, it may lead to cultural abeyance and as a result to a crisis in society because every tradition resisting for development and progress is condemned to self-beating. Renewal and modernization is of the natural characteristics of human being. For this reason, accepting changes and evolutions entails society equipment as a first prerequisite of any technology. This was the origin of social reconstruction as a strategy for reducing crises.

Social reconstruction is a philosophy that focuses on social changes occurring. The major goal of this idea is to achieve social and justice equality through familiarizing the social systems and preparing the societies for accepting the changes (Smith, 2014). In social reconstruction, the goal of education, training and even cultural organs is to commit and believe the need for change and correction in all fields. Therefore, educating and training the students and people is not limited to "whatever there is" or should not be. Thus, reaching the dream of "it should be" and being ready for change are very important for them (Sedgi, 2014).

Social reconstruction is one of the potential strategies for dealing with the social crises originated from social, economic, and technological developments. Social reconstruction means creation of readiness among all people especially youth generation. Since the creation of readiness has to be started and organized by educational organizations, thus social reconstruction is one of the ultimate goals of education and training institutions and higher education centers as well as universities. This article intends to survey the role of universities in social reconstruction in Iran.

\section{Social Reconstruction Theory}

This educational philosophy can be accounted as subcategories of pragmatism and progressive because its main emphasis is on change. The advocates of social reconstruction claim that they obey the John Dewey's pragmatism that emphasize the need for reconstruction of individual and social experience. Reconstruction followers, inspired by the Dewey's emphasis on the social reconstruction, insist the rebuilding of social and cultural experiences (Gutek, 2001). Social reconstruction has emerged from the research of pragmatism and progressive for social, economic and political reformations. This school puts its emphasis on the fact that the school should be the factor for social revolution.

\section{Pioneers of Reconstruction Philosophy}

George Counts (1974-1889) encouraged the social philosophy. Counts in his book named 'Does the school have the courage to create a new social order?' posed a question that created a challenge that continues up to the present time. He believed that "education and training is always subject to time, place and positions" (Gutek, 2001) that reflects "hopes, fears, and wishes of certain periods of history" (Gutek, 2001).

Brameld (1904-1978) is almost the most influential person in reconstruction philosophy. He is the author of Toward a Reconstructed Philosophy of Education and is of the adherents of this standpoint. He believes that study of a present society should be one of the important element of general education. Students of education major must much more study the sociology of education and social mobility. This attempt caused that the education and training has been accounted as social science branches (Sobhani, 2012).

Toffler is also one of the contemporary pioneers of social reconstruction. He writes in Future Shock "In order to help human beings for skipping the future shock out of their heads, we should create a post-industrial education and training system. To do so, we should search for our goals and methods in the future instead of searching in the past". Toffler in Learning for Tomorrow writes: "Education and training is not a matter that could happen in human's head but it involves all the members, senses, glands and all our biochemistry and originates from cooperation of a person and situation." (ali sobhani90.blogfa.com)

\section{Emphases of Reconstruction Followers}

The adherents of social reconstruction theory have dreamed the change and rebuilding of a society. Their dream has the stem in the philosophy of pragmatism, liberalism ideology and utopia. Accepting the pragmatism philosophy with emphasis on John Dewey's experiment and following the liberalism and utopia caused that reconstruction followers present a social picture for an ideal and changing society (Toffler, 1982).

This theory claims that the new society experiences a deep crisis because of its insouciance for fundamental 
cultural restructuring. The root of this crisis is consisted of the dissociated human values of social and economic realities. Genius of human creator, scientific and technological tools have been provided the dynamicity that underlie further developments. In their pinions, begrudging over past non-concern deeds is like a strategic cover that the modern conservatives utilize it to preserve the status quo (Gutek, 2001).

Proponents of social reconstruction argue that issues such as the increase in population, environmental pollution, violence and terrorism are symptoms of the current epidemic crisis. Guaranteeing the continuation of human life and creating more human-like civilization should be based on the fact that the human beings transform to the social engineers being able to plan the revolution route and utilize the science and technology for achieving the optimum goals. The adherents of social reconstruction have seen the contemporary society with a crisis arising as a result of human beings' indifference toward rebuilding organs and their own values in order for providing the new life needs. The human beings takes steps into a new science and technology era with their values and attitudes taken from the past rural life and forward industrialization. To solve this crisis, it is essential that the human beings review their heritage and identify the indelible and useful elements. Since the heritage is reviewed by the people, they intentionally plan the revolution route and make their plans fulfil. They can bring about new modern social order (Gutek, 2001).

Gutek believes that education and training should be propagated based on social reconstruction having observed the following matters (Gutek, 2001).

1) Investigating the cultural heritage critically;

2) Commitment to attempt to do social reformations intentionally;

3) Approach to planning in a way that outline the cultural reviewable route;

4) Testing cultural plans by means of executing social reformation programs;

To Manavipour, the schools base on social reconstruction theory are question-centered, that is, they identify the acute and critical community issues and then investigate the possible solutions. Being pragmatic is the major feature of these schools (Toffler, 1982). Philips (Manavipour, 2010) claims that the social reconstruction theory deals with the reformation and renovation of schools in order to formulate the policies and programs. They suppose the theory the reformer of the social system that should restructure and renovate the society. The reconstruction followers know the school as a social organ having to persuade the learners to live in group by means of intentional preparation of skills, knowledge and the best knowledge of society.

The reconstruction followers document their claims by pointing to the various conflicts in human community such as poverty, richness, environmental pollution, racism, population explosion and etc. They emphasize that the only way to get rid of these conflicts which brought about war and bloodshed is to improve the society reconstruction. The social engineering is looking for humans with this trait, thus schools have to treat the social engineers (Toffler, 1982). So, it should be said that the society as a social system moves first toward the entropy which is a characteristic of every system. Second, the society is facing the changes that its understanding is not possible with previous approaches. Therefore, the academic centers as interior balancing mechanisms of society should prepare the members for mentally accepting the changes and being up-to-dated for getting along with cultural and cross-cultural changes. Otherwise, they may lose their patience in dealing with changes so that they may give up. Kneller (philips.1995). States that coaches have to go through a detailed and comprehensive youth training program for social reform. For Counts, the big crises of $21^{\text {st }}$ century are signs of periods of deep transformation of rapid change. Since the American community moved between to different social patterns, the acute cultural revolutions emerged. Fast movement on the very complex, industrial, technological and scientific lifestyles puts aside the more traditional farming, local and rural communities. Although these revolutions appear material in the first sight, its social, ethical, political, economic and religious as well as artistic aspects have been affected (Gutek, 2001). It seems that what entails the necessity of social reconstruction are the crises as a result of technological changes, communities' industrialization and at this moment the side effects of information and virtual era. According to Counts, the evolution per se does not establish crisis. The crisis occurs when the people do not get ready for facing the changes and its outcomes. Counts utilized the Cultural Lag theory in his analysis. When technological creativeness surpasses the moral consciousness and social organization, cultural lag happens. Organizational crisis comes about by a long series of conflicts between the attitudes and values on the one hand, and technological innovations on the other hand (Gutek, 2001). Undoubtedly, the Industrial Revolution is one of the most influential factors related to the change and evolution of human lifestyles that impacted the culture, politics and moral patterns that could provide big crises overlooking the social reconstruction. According to Toffler, the industrial system is a thing more than just chimneys and factory production line as well as mass productions. It consists of a rich multi-aspect system that affected all the aspects of life and all the characteristics of first wave (agriculture) (Kneller, 2000).

Galbraith also believes that a working class cannot play a role in the post-industrial community for creating the social changes. In his idea, industrial revolution just begins from universities. In the post-industrialized society, the 
knowledge and information are the sources of power and ability and the major social changes take shape from the scientific and information findings and their consequences (Toffler, 1980). Therefore the post-industrialized society is another factors causing change in society that have the significant transformations with itself. If the community overlooks its reconstruction role, it faces some difficulties. Such communities are severely dependent on the universities for providing human sources. If the universities cannot make them social engineers, they may face many problems. 1980):

Hamilton states the key elements of industrialized and post-industrialized community changing as follows (Toffler,

1- Decline in employment in agriculture, mining, mining and industry sectors;

2- Increase in employment in the service sector;

3- Rise of science and technology as key components;

4- Emergence of new social groups that are characterized by non-economic factors, such as the rise of ultramaterialism, the new working class, technocrats and etc.;

5- Specifying the importance of information;

6- Reduction of traditional class conflicts.

\section{Social Reconstruction and Crisis}

Based on the materials for reconstruction theory, we realize that the major goal of the social reconstruction is to prepare the public opinion for preventing the crisis creation. Thus, in the case of this article's aim which is to investigate the role of universities in social reconstruction, we first survey the crises of today community, then investigate the role of university in social reconstruction considering the intended crises.

\section{The Concept of Crisis}

The concept of crisis is a vital and sensitive discussion in terms of understanding, cognition, and its solution for the governments especially for the countries that experience the transient periods (Ghaffari, \& Ebrahimi, 2010).

As mentioned earlier, according to the cultural lag theory, the crisis happens when the technological creativeness surpasses the ethical awareness and social organization of human beings. Therefore, not being in step with the cultural and social growth with technological growth is the major reason for happening a crisis that usually is the side effects of passing from one era to another. For instance, passing from the agriculture period into the industrialization period, passing from the industrialization period into the information era, and from the information era into the virtual era.

As Rabiee (Ghaffari, \& Ebrahimi, 2010). States, the world in the brink of third millennium have seen many conflicts and crises in the national level because of the high speed of evolutions as a result of communication revolutions and also new and modern reformulations of global order and its influence of the post-national domains and put an inevitable crisis for communities like Iran. Fastidious and scientific looking to the social layers of today Iran may shows many maze-like crises, visible and invisible. As if the today society of Iran is seeing metamorphosis and so called full skin molting.

\section{Level of Development and Its Relation to Crisis}

Rabiee (Ghaffari, \& Ebrahimi, 2010). Categorized the communities into three types in terms of development level.

1- Communities that are backward and are spending that time.

2- Communities that are executing the programs for quitting from backwardness and moving toward development. These communities are called transition communities.

3- Communities that have passed the period of transition and are known by development characteristics.

By authors' opinions, this categorization is a relative one because it cannot be said that the developed communities do not face a crisis in the era of accelerated knowledge and technology and entering the virtual era or not transiting. Anyway, if we accept the abovementioned category, Iran is accounted as the second category. The countries involved in the second type are naturally facing many social crises because they may experience more technology evolutions. Therefore, happening crisis and pressure as well as force are naturally much more in these countries. For this reason, the necessity of social reconstruction is very important and entails a specific priority such as in Iran.

\section{Phenomena of Crisis-Making in Iran}

The crisis-making phenomena can be categorized under three topics: 
A) Internal crises caused by the "chaos of the world modernity" that its factor is beyond the borders of a country.

B) Structural evolutions that are accounted as an internal phenomenon with possibility of accepting changes from outside.

C) Population evolutions that are internal matter. (ibid.)

\section{Crises Caused by World Chaos}

In relation to the first phenomenon, some critical matters can be investigated in line with some important happening that are intermixed. To Rabiee (Ghaffari, \& Ebrahimi, 2010), the studies show that the communities like Iran are moving forward with a transmutation named trouble-making transmutation. For James Rozena (Rabiee, 2008), there are five tendency in the main system of this trouble-making transmutation, such as 1- The tendency referring to the transition from industrial order to order a post-industrial order; 2. The emergence of social environmental issues such as air pollution, terrorism, drug trafficking, currency crisis, AIDS, etc. 3- The crisis of reduction in authority power; 4- Weakening the overall systems such as governments; 5 - The consequences of the tendency for globalization and integrity.

According to James Rozena, the below mentioned crises could be accounted as world chaos:

1- Massive change of social organs and destroying the traditional reference groups: because of shortening the time and place dimensions and eruption of information among the downstream groups of a society and growth of their expectations, of change-wanting, young periods, more-wanting and other-wanting that if they are not managed and controlled, a wave of crisis overflows toward the community.

2- Change in lifestyle and accepting the lifestyles of technological countries and moving away from the traditional and religious life that the useful, appreciate and original values of community are also targeted.

3- Taking western and alien patterns instead of Islamic, Iran, native and regional patterns.

4- Mutual dependence: nowadays countries cannot say that we can manufacture by ourselves. Today the theory of Self-Sufficiency is neither practical nor rational. The concept of mutual dependence is passing from economic route and lead to social and political interdependence, dependence of blocks, coalitions, and beyond it the dependence of organizations and social organs inside states with each other and with the exterritorial organizations. As it goes today, if the military, political and economic powers cough, the third world states afflict pneumonia (Ghaffari, \& Ebrahimi, 2010).

The interdependence (mutual dependence) level has been promoted from national level to transnational levels, that is, today all levels are moving toward the globalized interdependence such as the transnational organs, the sub-national organs and even the individual levels. This is new happening that is related to these recent years and not past. (Rozena, 2003). According to the abovementioned materials, the dependence of people especially youth generation on the other countries instead of our national sovereignty and bias is one of the other threats and crises.

5- Penetration of terrorism and extremist religious groups: Terrorism is one of the great threats that needs global determination against it. Based on the Global Terrorism Index (Database; GTD), the number of terrorism victims has been raised five times in the world from 2000 (3361 victims in 2000 to 17958 in 2013) [15]. By the account of increase in terrorism activities of Daish, The Taliban, Boko Haram groups and etc. the statistic has increased significantly in the present year. To this report, the $82 \%$ of victims are in five countries of Iraq, Afghanistan, Pakistan, Nigeria, and Syria. As three of these countries are neighbors of Iran, unfortunately the threats are facing Iran too (Mundell, 1998).

To this report, the countries that have the great statistic of terrorism have three unique features:

A) Social hostility between different ethnic, religious, and language groups;

B) Lack of consistency and high level of dissatisfaction among a group;

C) The existence of state violence, including extrajudicial killings, political assassinations, gross violations of human rights, crime, and etc.

6- Drug and Addiction: The problem of drugs is the problem of many years ago that people are dealing with and it aims very much hurts over human communities' body. More than 200 million people are dealing with this disaster. This disaster is accounted as an international threat (journalists club)

7- Global and modern Media (Internet, Satellite, Internet Networks)

McLuhan claims that work and life change totally under the aegis of communication and electronic. The communities and nations are getting closer to each other and finally a village will be created in the size of earth. Undoubtedly, closeness will cause many inundations of data, information, and various programs from all over the world which will cause cultural changes in various domains of their life (Zohuri \& Hosseini, n. d. ). In 
terms of daily increasing of these media, McLuhan claims that the education methods of today is not compatible with the world realities. He knows the crises of universities as a result of incompatibility of educational system with the electronic conditions. He recommends that it is essential to reconsider the methods and syllabus in order to meet the needs of today society. He believes that our era has been faced a revolution and the reason for academic crises is the negligence of evolutions that are resulted from electronic media (Azin \& Pirmohammadi, 2008). According to the studies done, the media especially the new social networks are the most influential tools in the field of ethics, behavior and culture of public opinion especially youth generation.

Azin and Pirmohammadi state that enter of satellite and internet programs in the developed world causes the acceptance of new thoughts and imported lifestyles methods among youth generation. This factor causes that the youth avoid many habits and traditional mores of their own community and tend toward the imitation of western culture. According to Frantz Fanon, they look for white effigies instead of their black skin and look for new life methods and western novelties and move away and away from what are based on their own cultural heritage and civilization (Dadgaran, 1998). The research studied in Iran also confirms this statement that modern global media are widely affecting ethics, behavior, lifestyle, values, culture, beliefs, identity and mode of operation especially young people ((Dadgaran,1998), (Azin \& Pirmohammadi, 2009), (Haghighi, 2012), Adlipour, Ghasemi \& MirTabar, 2014)).

8- The Crisis of Reduction of Family Power and Institutional Authority Power:

From two decade ago, the capability of formal organs has been gradually decreased in dealing with achieving the desired solutions. This crisis is not just specific to Iran. It is good to say that its extent of influence is different in the developed and transition countries as well as under-developed ones. This crisis is not purely mentioned in organization level. Today, there is some power and obligation to obey among every social organ. For instance, the range of obeisance is decreased about five to ten years among youth people in the smallest social organ like a family. This crisis gradually becomes epidemic toward the secondary groups of society. As the nature of work and occupation has become more professional and the role of workers and engineers is more highlighted, the traditional organs cannot manage the economic and political sources of community as usual (Rabiee, 2008).

This crisis causes that the power of influencing of the reference groups such as national-regional-parental dominance becomes less on their under controlled people that this matter can have much more crisis. For this reason, often we see that the programs and activities are done against the normal rules and regulations under the pressure of low classes. Often the states lose the capacity of leading and control of many affairs.

Another happening that has occurred in the dominant crisis is the change of information sources related to the social groups. In the past, the government was the biggest and most important provider of information sources and easily canalized the information at the advantage of community. But in the recent decade, the emergence of modern communication media, news and other types of them is one of the powerful opponent for the governments and gradually is replacing with the native ones. According to Manuel Castells, the network community emerged, the dominance of states decreased, and tended toward the new people-centered groups ((Javadi, Azizi \& Ansari, 2013), (Rafipour, 1999).

\section{Second Phenomenon: Structural Evolutions}

\subsection{Urbanization:}

The increase of urbanism is one of the happenings related to the structural evolutions in Iran. The proportion of urbanism to rural-living has become inverse from 1966 to 1996. The statistic shows that this procedure is growing and it is predicted that it increases in the consequent years. Urbanism has its challenges and crises. The apartment-living culture is quite different with that of the traditional culture. New norms and more inconsistencies has been emerged. These issues in overall create part of the social crisis of today Iran (Ghaffari \& Ebrahimi, 2010). Beside these evolutions, the issue of marginalization, how to spend leisure time, type of employment, transport, poverty, addiction, and various crimes are the result of population density and the result of caused crisis by the population density.

\subsection{Increasing Literacy:}

Is the second happening in the structural evolutions? However it is an independent variable, it always carries modern phenomena and variables. When the percentage of literacy increases, the number of professors, students, jobs related to university, applicants of blue-collar jobs and professional jobs. On the other hand, the level of expectation and needs of 
the educated class from the government, as well as their cooperation level is very different from those of the uneducated people.

The research carried out in this field has shown that value changes and political and social changes has been relevant with the increase of literacy percentage (Ghaffari \& Ebrahimi, 2010). Every generation has its own heroes and specific patterns as well as different wishes. These mental requests will be simple and initial when they are not in line with the literacy and urbanism. In that case, it was not crucially crisis-making. The mental and initial patterns and needs do not have the potential of change and even request for change. In the today community of Iran, the increase of urbanism is combined with the literacy growth and spread of transnational communications so that it leads into a creation of pattern, needs and wants different from those of the past and even contrary to the intended politics of the government (Ghaffari \& Ebrahimi, 2010).

As considered above, there are modern shares and inconsistent mental patterns with formal valued and normrelated creation in the political system of Iran. The process of intellectual is expanding. It is gradually and constantly changing the present culture for and daily increasing incorporation for global cultural process and mental and cultural transnational groups that can be easily sensed with a scientific point of view.

\subsection{Changing the Manner of Living:}

The third crisis-making mode in the field of structural revolutions is related to the change of living manner. A glimpse to combination of jobs shows that the structure of occupations has seen a significant difference after Iran's revolution and especially in the two recent decades with enter of new technologies and mass productions. In that condition many jobs have lost their philosophy and instead added the producers with new jobs. In the past, the traditional life especially in the rural areas had its own jobs and the economy of a family was involved all the members of that family. Nowadays, the mechanization of agriculture and animal husbandry have been changed the business of villagers. This made that they lost their jobs and migrate big cities and villages. The manner of their living has been totally changed in the urban areas because of the industrialization growth and industrialization of many jobs. For this reason, the migration of villagers to the cities and the addition of number of job applicants in cities and the encounter of unusual and unconventional norms have caused many anomalies such as unemployment, irrelevance of jobs with literacy extent, the crisis of lag between social classes, the crisis of margin against text, population density and its problems. Conflict between tradition and renewal is also a crisis-making aspect. To Guilans, traditions like nature were considered as an external framework for the activity of human being in the past. But now we should decide about the traditions and say to keep which one and put away which one (Toffler, 1980). Thus if the procedure of reconstruction is not taken place in the manner of living, and the school and university cannot mentally restructure the people, the living manner is converted into a trouble-making crisis.

\subsection{Globalization:}

There are many evidences and reasons in various domains of economy, politics, culture and society in the micro- and macro-levels that indicate the trueness of globalization process, as follows:

1- The development of financial markets and the global market;

2- The framing of electronic commerce or economics or without weights;

3- The expansion of the role and influence of multinational corporations;

4- The internationalization of production process;

5- Observation of human rights and global civil society

6- Transnational NGOs;

7- Formation of a global movement to combat environmental pollution.

Guilans has considered the impact of globalization process from the viewpoint of pressures that involved in the various dimensions. In his idea, globalization involves a set of opposing forces that introduce it in the form of triad charter. He categorizes these forces in the forms of pressures from top to down, from down to top, and pressure to both sides. For instance, these pressures constantly challenge the community: the pressure of global market on the nations (from top to down), new movements inside the nations such as nationalism (from down to top), and formation of new social, cultural and economic areas that go beyond the national borders (pressures to both sides) (Rabiee, 2001)

In the opinion of Waters, 1- globalization is the processes of differentiation and homogenization. It leads the world to the pluralism by the acceptance of microcutures and local abilities. 2- Globalization weakens the conventional norms between nation and state and leaves the ethnical minorities alone. It may recreate the nations in the all over borders of previous government. 3- Globalization takes the center into the sides. If it is fed from the western renewal, there exists 
some facilities for new ethical identity in the surrounding culture. The route of this cultural flow is the result of electronic and abundant tourism. 4- Globalization takes the sides also to the center. For instance, the economic migrants move from the less prosperous sectors to the more prosperous ones (Giddens, 2000).

Therefore, globalization can influence significantly the community and if the community is not ready for its acceptance, it may wonder in above-mentioned crises.

\section{Third Phenomenon: Demographic Change and Youth}

Another phenomenon is demographic and population evolution that has occurred in Iran. This type of evolution rarely happens in other countries. Although most of the world countries are experiencing population crisis, this topic has been happened more obvious with more velocity in Iran in such a condition that the population of Iran is turned into the young people different from two decades ago (Ghaffari \& Ebrahimi, 2010).

The comparison of Iran's youth population with that of other countries makes it obvious that the ratio of Iran's young people is in a special rank among other countries. For example, Iran has the first rank for 15 to 19 years old, fourth rank for 20-24 years old, and second rank for 25-29 years old. (Rabiee, 2008) According to the system and Iran's leader policies as well as the prevention plan to reduce population growth submitted by Parliament, it seems that the population combination of young people is increasing. However we cannot judge about consequence of increase or decrease of population combination in the years ahead, having large deal of youth ages may have its problems that universities and education centers have to prepare the students for facing the crises. There are some matters for young people as follows:

1- Employment and Unemployment Question: over $60 \%$ of the youth have stated their problem about proper job and enough income (Waters, 2000). 2- Job Distribution: Montazer Qaem in his study has shown that $80 \%$ of working people in Iran are male and $20 \%$ are female in 2001. The statistic shows that the number of females entering university is more than males. In Iran the education does not play a role in the job of the youth and processes show that the rate of unemployment is increasing among educated youth generation (Waters, 2000).

3- Migration or Request for migration by Educated Young Generation to Other Countries: According to the annual census, many students migrate and even those students that migrate using scholarship return to their countries in a few number. According to IMF, Iran has the first rank among other countries for brain drain (Ghaffari \& Ebrahimi, 2010). Alongside the above-mentioned matters, the other matters such as the housing crisis, demand for education, the increasing demands of the youth in the political, social, cultural and economic fields and etc. are also related to the problems of population combination that are discussed in other place.

\section{Natural and Environmental Crises}

\subsection{Water Crisis:}

The ware resources are in critical stage in the world. The problems of water deficit and its quality have been brought about many matters for the world. The limitation of sweet water resources and physical accessibility of water and sociopolitical crisis have become a serious problem in many countries. Reduction of water resources can also overwhelm the growth of other countries because the growth of many water-related industries such as plants and agriculture sectors may stop or reduce working. As a consequence, it may affect the other sectors.

The fast growth of population is the most important factor for capitation reduction of reusable water in the 80 years ago. Iran has become about 6.8 time bigger over these periods. According to the studies, the capitation amount of renewable water has been dwindled from $13000 \mathrm{~m}^{3}$ in 1921 to $1900 \mathrm{~m}^{3}$ in 2006 (Montazer Qaem, 2005). It may become less in the near future because of the less raining. According to another estimation, the annual reduction of internal sources of sweet water is about 5.5 times in contrast to rich countries, 3.7 times to poor countries, and 8.9 times to mediocre countries (Ehsani \& Khaledi, 2003).

Water crisis is one of the crises that should be recognized by academic centers which will have many social, political and economic problems and consequences in the future. If it has not been controlled by the educational and academic centers, it may destroy the foundation of everything.

2- Crisis of Destroying Environment: The problems of environment have become a global and endemic crises (Pirzan \& Honarbakhsh, 2008). This situation is the result of some factors like excessive use of natural resources, population growth and technological progress of mankind. The major victim of this situation is the environment. The result of this destruction that often happens unintentionally causes the death of creatures. In these conditions, the life of human being is in danger, but also the aim of human being faces problems for reaching the continuous and sustainable 
development (Hejazi \& Arabi, 2008).

Although many organizations today formally assume responsibility for environmental protection, many number of governmental institutions are establishing to fight the destruction of the environment, it seems that the most important role are for universities and training centers so that they can make believe and support the environment. In fact the society should be trained in a way that every act of environmental protection should be a norm for people, because the destruction of environment occurs due to indiscriminate use, factories' waste, waste of life or in any case manipulation and change in nature by men. So if people are well trained, the environment does not destruct, but also deliberately it could also be developed and optimized. Therefore, in the direction of development, universities and training centers should cooperate as soon as possible and before any disaster to restructure socially so that they develop and optimize the environment actively.

\section{The Role of Universities in Social Reconstruction}

As mentioned in the previous discussions, the coaches who follow the theory of social reconstruction, see the social problems as a question. In this approach, they pose some key questions:

1- What are the significant elements distinguishing the culture and understanding? , 2- What are the troublemaking fields influencing the society? How can they be solved? (Gutek, 2001).

Accordingly, reconstruction followers present the idea of question-centered universities and schools and see the schools as centers that teachers and students are dealing with pragmatic research and problems as well as with doing academic research. In such centers, research orientation, large issues of social, political, economic and educational are under magnifier. The reconstruction followers are trying 1- to put schools in the center of community. 2- To use schools or institutions as tools for change and reform in order to take advantage. 3- To identify the current issues of social, political, economic and cultural (ibid.).

In this regard, the scopes of the problem-making or crisis-making, in reconstruction followers' saying, have been investigated. Given the problems of reconstruction, the following role are explained.

1- Identifying, training, and guiding the new reference groups in the direction of Islamic-Iranian society's optimum values: As mentioned, one of the crises of modern societies is the crisis of decrease of traditional reference groups. So, one of the tasks of universities is to guide the new reference groups to the ideas and values of the community, to provide the necessary training to students about conservation and perspicacity of the desired values, and probably the absolute ones, and to do research on the field that How can traditional values be presented in new form in accordance with international developments for the youth and public opinion. There is a close connection with the people of traditional reference communities in order to adapt the people with the new molting, while maintaining the objectives and the religious, national and legitimate values of community, in this within the role of universities is the adaptation of original values with the emerging global approaches.

2- Refining and rebuilding the past values and according them with new valuable creations in society: Dewey believes that school has three main duties in relation to the values: simplification, purification, and balancing. According to this view, another important role of university in connection with the reconstruction is to simplify and purify the emerging values and then to balance it by restructuring value of the community, especially before the youth face the risk of causing harm. On the other hand, skillful reconstruction of traditional values and coordination as well as balancing them with new and emerging values are needed.

If the University is able to refine the new values and to coordinate them with valuable construction of society, and to upgrade constantly the values in the new format and appropriate to technological change, the community will not experience crisis for sure.

3- Restructuring the Islamic patterns and texts: Third role of universities is to express the Islamic-Iranian texts in aesthetic, artistic and appealing forms to the new generation. We can now observe that many of the philosophical and social views that already express by contemporary scholars mostly Western, once was presented by Islamic prophets like Prophet Muhammad. But the new generation and even academics have succumbed to Western views that they have forgotten their native patterns. For example, Mohammad said that first seven years of a child is the lordship period, but now we know Rousseau as leading in child caring. That's why the younger generation totally enthralled in the west culture because our university thinkers do not work on these rich patterns and texts. Thus, another role of universities' reconstruction is to strengthen the Islamic and Iranian patterns.

4- Strengthening the sense of attachment to national and bias sovereignty: In the crisis part, it is discussed that one of the effects of this era is the mutual dependence of communities in terms of the growth of technology, 
communication, economy and development of multinational companies and the interrelatedness of social and political that in this context of probability of poor and Third World countries to more developed countries increases. Therefore, to prevent or reduce the impact, it is necessary that the cultural and academic centers restore and strengthen the sense of dependence to national sovereignty and bias and redefine sovereignty and the type of communication that should have been dealt with other nations. But if we enter this new world with old definitions without restoring national pride and sovereignty, we surely experience the dependence on the imported values and distancing from national pride and sovereignty.

Another identified crisis that now threatens the country is the crisis of terrorism and religious extremist groups. According to the report (Mundell, 1998), states that have the highest number of casualties caused by the influence of terrorism have the three characteristics in common:

A) Social hostility between different ethnic - religious - language groups

B) Lack of cohesion among group in high level of inter-group dissatisfaction

C) Existence of violence, including ascending killings, terrorism and human rights violations - crime

Accordingly, it can be mentioned three other roles in the restructuring the universities.

5- Reconstruction of Cultural Coexistence between different Ethnic, Religious and Linguistic Groups in: In Iran, there live many tribes such as- Kurd, Baluch, Lor, Turk, and Turkmen with different religions. At universities, students live together no matter of differentiation in color, skin and language. Emphasizing the national and religious commonalities and preservation of the honor of the country can help to strengthen the sense of coexistence.

6- Production of Integrated Contents and Texts: One of the other roles in the direction of social reconstruction and reduction of hostility and differences between the groups is to produce some texts that help unity among different people and religion. Unfortunately, commonalities do not highlight in many produced cases. For example, there are many commonalities between Shia and Sunni. Often seen, each group tries to prove its superiority over the other and introduce the other as anti-religion. These differences make that a group for highlighting their religion introduce the other religion as very ugly and extremist. This causes the extremism and finally opposition and terror to each other. The universities should be free from extremes and try to convince both sides that each of them has its standpoint and advantages.

7- Strengthening the free-thinking tables: Another role of university reconstruction is to strengthen the freethinking tables that is also comments of Iran's Supreme Leader. The result is that students learn to discuss the scientific matters rather than physically contending against each other that can turn into a pattern and a typical behavior in a long run. This can vaccinate the students against the imported culture and foster a spirit of criticism in students as well.

8- Developing and training the life skills appropriate to the effects caused by industrialization and transindustrialization: It is earlier mentioned that factors such as addiction, poverty, divorce, loss of traditional authority power, unusual relationships, increased leisure time and etc. are the crises in the developing countries. Thus, one of the critical roles of universities is to restructure and develop the skills and create the lifestyle workshops. The workshops can vaccinate the students against these ills.

9- Recruiting human sources in the age of information and technology: Another role that can be counted for the universities in terms of social reconstruction is recruiting human sources in the age of information and technology because in the information age, many affairs are directed electronically and many of the economic, social and political affairs are done in cyberspace, so if universities cannot provide the manpower needed by society in this era, many of the matters will be slowly performed or take toward the closeness so that no global connection can be maintained.

10- Establishing Software in the modern world media: As mentioned earlier, the global development of new media including satellite, Internet and social networks caused that information delivered freely in the hands of young and middle-aged people which is against our culture, customs and policy. Therefore, we cannot establish the same spaces compatible with our policy for the youth, some social crises may have arisen.

11- Institutionalizing the respect for laws and regulation among adolescents: Since one of the crises in the contemporary society is the crisis of authority and reference, thus it is necessary that a process be considered in the universities that a sense of responsibility, social and political compliance is empowered in adolescents in order to do the affairs of people and non-governmental in the community without any chaos. Otherwise, due to the weakening of the authority and power of central states and traditional frames and failure to comply the laws and regulations will produce anarchy.

12- Strengthening religious and value norms and redefining them: The collapse of beliefs is the first stage of 
crime. Therefore, strengthening religious beliefs and community value is the best way for preventing social damages that takes the human being to the high life (Ahmadi \& Hajinejad, 2010). Thus, by strengthening the religious norms and values and their redefining may prevent many social ills such as drug abuse, divorce, brothels, unveiling, character assassination, theft and embezzlement, and environmental degradation. In this regard, one of the more important roles of universities should be strengthening the religious values and norms accepted by society.

13- Strengthening the belief of rural life versus creation of negative attitudes toward urban life. One of the problems and crises that has put its effect on the lifestyle, livelihoods, change of political, economic and social community values is the increasing of urbanization in contrast to the rural population reduction. According to Rural Development Deputy of Vice President, we have 34000 free-of-people villages in Iran (www.tabknak.ir). Therefore due to the complications of the issue mentioned earlier, strengthening the belief of rural life and its advantages should be put in the formal and informal courses of students.

14- Preparing a comprehensive rural life program: One of another roles of the university in related to reducing rural migration to urban areas can be preparation of comprehensive plan for rural life by professionals in collaboration with the administrative centers of the country, so the attractions of rural life make reduce the migration of villagers. Clearly, if such a plan is successful, a big part of the problems or the crises ahead will be resolved.

15- Changing the educated adolescents' attitudes towards occupation: Since the population of the youth increases, the number of unemployed people increases. On the other hand, since the literacy level increases, the expectation of the youth increases for requesting white-collar jobs. Since the development of technology and virtual jobs decreased the need for human sources, the view of public opinion especially the young people should be change toward the jobs. They have to create self-work and entrepreneuring instead of waiting for government's full support. They should just expect some grant packages from the government.

16- Training entrepreneuring: Although some universities have taken entrepreneurship as an academic discipline at higher levels of education and there are some courses during the academic years, it seems that entrepreneurship has some difficulties for graduates. That is why it is necessary that universities have more serious determination for entrepreneurship education through formal and informal programs, and entrepreneurship be effectively part of the curriculum.

17- Admitting and introducing elite graduates for scientific and administrative bodies: One of the concerns that put devastating fist to the country's human capital is mainly Brain Drain phenomenon or migration educated people that will primarily become high-flier people in the target society. This phenomenon has caused billions of dollars investment in the other countries. Therefore, it is the responsibility of the universities that support their working conditions immediately after their graduation with the assistance of organizations. One of the ways for their employment is to register them as stuff border or introduce them to executive administrators to use their potentials. In this regard, both the abilities are used and the wealth and creative sense of are remained in the source community.

18- Strengthening native self-esteem in the world scenes: Globalization puts pressure on the different aspects of the society from social, political, economic angles. Its influence is inevitable because of its incompatibility with the community culture. Therefore, acknowledging the positive effects of globalization, the survival of indigenous values and culture should be pondered. The role that universities and training centers play should be to strengthen local self-esteem in steps with same globalization. The Islamic-Iranian culture is rich enough that it may not knell for the imported cultures if it will be trained for public opinion. Without any doubt, religious and national education causes self-esteem against cultural invasion.

19- Strengthening the culture of consumption of natural resources especially water resources: Although the variety of natural resources due to population growth and indiscriminate use are finishing and becoming critical, the water is one of the sources that sees little government control. For this reason, the role of every people is more salient and practical in controlling, storing, and optimizing. In this respect, the academic centers should have comprehensive plan for creating belief and economical attitude towards the water. This program should take into action the students of water-related courses who will undertake the projects of engineering and agriculture in the future. in the work and life of attention to it as one of the criteria for sustainable development and crisis prevention, especially for engineering students who will be responsible for the implementation of projects, Engineering and Agriculture. In this event, they would be agents to solve the crisis based on their career and personal life and social factors.

20- Creating environmental attitudes among students: Undoubtedly, one of the crises facing our society and 
following the global community is the environmental crisis. Although the role of people-centered organizations advocating the environment has been very hopeful, we are far from reaching the ideal situation. Universities and educational centers can create an environmental attitude among the formal and informal programs to bring about great evolution for preventing the environment crisis.

21- Creating and strengthening the culture of resistive economy among students: One of the critical issues that had a profound impact on Iran's economy by the world powers that has been intensifies in the forms of sanctions in the last few years because of the pretext of the Iran nuclear file. The best approach to this crisis has been more the idea of resistive economy expressed by Supreme Leader of the economy for the first time in September 2009 at a meeting with entrepreneurs (Amini, 2012). Therefore, the most cost-effective and safest approach to global threats especially the economic sanctions is to clench the resistive economy. Resistive economy has various dimensions that one of its main dimensions is to create the native and domestic attitude for solving the economic problems in society especially the students who are the authority of the future. So one of other roles of universities in dealing with the social reconstruction is the creation of culture for resistive economy during the formal and informal programs.

\section{Conclusion}

In terms of universities' role in social reconstruction, it can be said that according to the social reconstruction theory, the role of universities as the education center is to identify the crises in society and to create some conditions to help to solve the intended crisis by the public opinion especially students. The universities also play an important role in solving the community crises by carrying out the necessary research and preparing mentally and pragmatically the students. In this paper, first the current crises of the society have been categorized and then 21 roles recognized for the public opinion.

1- identifying, training, and guiding the new reference groups in the direction of society's optimum values; 2refining and rebuilding the past values and according them with new valuable creations in society; 3- restructuring the Islamic patterns and texts; 4- strengthening the sense of attachment to national and bias sovereignty; 5- Reconstruction of Cultural Coexistence between different Ethnic, Religious and Linguistic Groups in; 6- strengthening the free-thinking tables; 7- restructuring the coexistence culture between different ethnic groups, religions, and languages; 8- developing and training the life skills appropriate to the effects caused by industrialization and trans-industrialization 9- recruiting needed human source in the age of information and technology; 10- establishing software in the modern world media; 11institutionalizing the respect for laws and regulation among adolescents; 12- strengthening religious and valuable norms and redefining them; 13- strengthening the viewpoint of rural life versus creation of negative attitudes toward urban life; 14- preparing a comprehensive rural life program; 15- changing the adolescents' attitudes towards occupation; 16training entrepreneuring; 17- admitting and introducing elite graduates for scientific and administrative bodies; 18strengthening domestic self-esteem in world scenes; 19- strengthening the culture of consumption of natural resources especially water resources; 20 - creating and strengthening the culture of resistive economy among students; and 21creating environmental attitudes among students.

\section{References}

Jalali, Aliakbar, (2014). Virtual Age: Fourth Change Wave. Retrieved from http://vista.ir/article. Smith, J. S. (2014). Social Reconstruction. Retrieved from http://www.academia.edu/1957998/social-reconstrouom.

Sedgi, (2014) A Look on Technology, Ethic and Culture Relationship. Retrieved from www.hawzah.net/fa/magrat/89/3421/16333.

Gutek, Gerald. L (2001) Philosophical Schools and Educational Ideas, Translated by Mohammad Jafar Pak Seresht. Tehran, Samt Pub. Sobhani, Ali Mohammad (2012). Social Reconstruction and Education. Retrieved from http:// ali sobhani90.blogfa.com/post/20

Toffler, Alvin (1982). Third Wave, Translated by ShahinDokht Kharazmi, Tehran: Nashre-No

Manavipour, Davoud. (2010). Philosophy of Education (School Mssion in Philosophical, Mystical, Psychological and Sociological). Tehran: Doran.

philips.d.c. (1995). The Many Faces of Constructivism. Amerivan educational Research. nza. pp5-12

Kneller, George. (2000). Educational Anthropology, Translated by Mohammad Reza Ahanjan \& Yahya Gaedi. Tehran: Ayizh pub.

Toffler, Alvin,"The Third Wave”,William Morrow and Company,Inc.,544 p. ISBN 0-688-03597-3, 1980.

Ghaffari, Gholamreza \& Adel Ebrahimi (2010). Sociology, social change, Tehran: Agra Pub.

Rabiee, Ali (2008). Social crises of today's Journal of Sociology, Vol. VIII. Number 3, fall 1386. pp. (51-80)

Rozena, James, (2003). Chaotic world, translated by Alireza Tayyab, Tehran: Center for Strategic Studies.

Mundell, Robert (1998). Changing face of national security: The Center for Strategic Research. Tehran: Institute for Strategic Studies. 
A comprehensive report of the direct and indirect effects of terrorism in 162 countries, journalists club. Retrieved from http://www.vista.ir/news/187802.

Zohuri Hosseini, Vahid (No Date). Afghanistan and the global burden of addiction. Retrieved from http:// iichs.org/foreing-policyarticles/afghanestan-va-mozal.docx

Azin \& Pirmohammadi (2008). Shiraz, Journal (sociology of organizations), social, Volume 1, Number 1, winter 1392, p. 83-102)

Dadgaran, Seyyed Mohammad (1998). Principles of Mass Communication, Tehran: Firuze Publication.

Azin, Ahmad \& Pirmohammdi, Kobra, (2009). Investigating the role of new media with emphasis on satellite and the Internet on students' cultural identity, a social science research, the second year, the second issue, summer 1387, p. 139-157.

Haghighi, Mohammad Reza (2012). Analyzing the Impact of Satellite on cultural identity of youth, Media Studies, Volume 7, Number 3 (a), fall 1391, pp. 51-63.

Adlipour, Samad; Ghasemi, Vahid, \& Ahmad MirTabar (2014). The impact of the social network Facebook on youth cultural identity, Isfahan, Iran Cultural Research Quarterly, Vol. VII, Spring, No. 1393, p. 28-1 1.

Javadi Yeghane, Mohammdreza; , Azizi, Jalil, \& Mohammad Reza Ansari (2013), The international media and religious identity in youth.

Rafipour, Faramarz. 1999. ((Change the values in the mirror and press the cinema)). Research a. Year 4 No. 14, $15,30,5$.

Rabiee, 2001, Sociology change: worth a look - the behavior of voters in June. 1997, Tehran: Culture and Thought.

Giddens, Anthony (2000). Runaway World: Discourses on global integration, translated by Ali Asghar Saeedi \& Yusuf Hadji Abdolvahhab. Tehran: Elm-o-Adab.

Waters, Malkum (2000). Globalization, Translated by Ismail, Annie Givi and Siavash Moridi, Tehran: Department of Industrial Management.

Montazer Qaem, Mehdi (2005). The role of information and communication technology in youth employment: the triumph of global experience and approach to Iran, presented at the Second Congress of Demography at the University of Shiraz, Iran. Tehran: Center for Strategic Studies and Research, Asian and Pacific Population.

Ehsani, Mehrzad; Khaledi, Human (2003). Agricultural water productivity. Tehran: Iranian National Committee on Irrigation and Drainage.

Pirzan, Sedighe; Honarbakhsh, Nazli (2008). Critical water situation in the world and Iran, quarterly strategy, $16^{\text {th }}$ year, No. 48, Summer 1387, pp. (193-212).

Hejazi, Yusuf; Arabi, Faeze (2008). Factors affecting the participation of NGOs in the protection of ecological environment, Journal of Ecology, 34th year, no 47, pp. (106-99).

Ahmadi, Ali; Hajinejad, Ali (2010). Environmental degradation is an obstacle to sustainable development, presented at the Fourth International Congress of the Islamic World Geographers, Zahedan, Iran: Persian date, April 2010.

Amini, Mohammad Nabi (2012). Religion's role in the prevention of social ills, speaking Saba. No: 8 \& 9.

Kamrnirad, Amirhossein (2013). Resistive Economy from Supreme Leader. Retrieved from: http://www. rasekhoon.net/article.html. 